\title{
An Examination of the Impact of Workplace Wellness Programs on Health Outcomes in the U.S. Versus European Countries
}

\author{
Lesley Clack \\ University of Georgia \\ Warren Fraser \\ University of Georgia
}

\begin{abstract}
Non-communicable diseases are a growing concern for older adults, which has led to the popularity of wellness programs in developed countries to improve the health and productivity of workers. While the U.S. and Western Europe have invested a significant amount of money on wellness programs, trends indicate that the U.S. still falls short in health outcomes. This study utilized online databases to analyze data on each country's average life expectancy and cardiovascular mortalities in comparison to prevalence of workplace wellness programs. Workplace wellness programs may be effective tools for impacting the health of a population once appropriate initiatives are incorporated.
\end{abstract}

Keywords: Workplace Wellness, Health Outcomes, Employee Wellness, Life Expectancy, Mortality

\section{INTRODUCTION}

The United States' economy has exceeded all other nations in the world with a Gross Domestic Product of $\$ 19$ trillion, and the U.S. spends approximately \$3.3 trillion per year on healthcare (Center for Medicare and Medicaid Services, 2018). While the United States' economy is ranked number one in the world, the health outcomes of individuals, such as life expectancy, remains inferior to that of other developed nations (International Monetary Fund, 2018). According to the National Business Group on Health, preventable illness is increasing globally and non-communicable diseases account for $63 \%$ of deaths annually worldwide (Greenbaum, 2011). According to the Centers for Disease Control and Prevention (CDC), productivity losses linked to absenteeism cost employers \$225.8 billion annually in the United States, which is equivalent to $\$ 1,685$ per employee (CDC, Worker Productivity, 2016).

Employee wellness programs have become more prevalent in the workplace globally, as evidence by a projected annual growth rate of $6.7 \%$ (Global Health Institute, 2018). Yet, only $10 \%$ of the global workplace, which is 321.7 million people, have access to workplace wellness programs (Global Health Institute, 2018). North America and Europe spend approximately equal amounts of money on workplace wellness programs totaling \$17.6 billion and \$17.7 billion respectively (Global Health Institute, 2018). The adoption of workplace health initiatives is a potential tool to offset the rising health risks and costs in the world. These programs have been incorporated to promote healthier behaviors, essentially reducing health-related costs and increasing work productivity. The impact of wellness programs on employees 
may differ among countries. By taking a comparative approach, we investigated the success of wellness programs on the overall health of individuals in the U.S. and compared the findings to that of Italy, the United Kingdom, and Sweden, which have greater health outcomes in terms of life expectancy than the United States.

\section{Workplace Wellness}

Workplace wellness initiatives are becoming more prevalent across the world, which may help to promote longer life expectancy and reduce non-communicable diseases. The CDC defines workplace wellness programs as "a coordinated and comprehensive set of health promotion and protection strategies implemented at the worksite that includes programs, policies, benefits, environmental supports, and links to the surrounding community designed to encourage the health and safety of all employees" (CDC, Workplace Health Model, 2016). More of the world's workforce are becoming unwell. According to the Global Wellness Institute, 76 percent of workers are struggling with their physical well-being (Global Wellness Institute, 2016). These trends increase employers' awareness as they are subjected to economic losses due to decreased work productivity. Hence, more companies around the world want to improve the health of their employees by adopting wellness initiatives to increase workers productivity.

Workplace wellness programs are becoming a very customary employee benefit in the United States. Data from the $5^{\text {th }}$ Global Wellness Survey indicated that wellness programs were most prevalent in North America, with 74 percent of surveyed organizations offering some form of initiative for its employees (Buck Consultants, 2010). As of 2018, there are 588 companies in the United States who provide some form of wellness programs to its employees and that number is projected to increase to 633 by 2021 (Statista, 2018). The larger companies that consist of more than 1,000 employees are more likely to offer workplace wellness programs than the smaller firms that consist of 50-100 employees. Studies suggest that wellness programs in the United States promote healthier lifestyles and manage current lifestyle epidemics. Long term wellness program participation lowered cardiovascular rates which in turn reduced health costs (Mattke, Liu, Caloyeras, 2013).

European countries have evaluated the effects of workplace wellness programs on the health of its employees. Researchers in Italy found improvements in cardio-respiratory fitness in a healthy and physically active population of employees (Biffi et al, 2018). Prior studies have also revealed that stress and mental health were the second leading cause of long-term absence from work in the United Kingdom. Employees in the United Kingdom perceived that workplace wellness initiatives improved their mental and physical health outcomes (Reward \& Employee Benefits Association, 2017). Findings in Sweden's wellness initiatives have suggested minute increases in general health outcomes (Gånedahl, Viklund, Carlén, Kylberg, and Ekberg, 2015). Whether minute or significant, other developed countries have experienced positive impacts of workplace wellness programs.

\section{Cardiovascular Mortalities}

According to the World Health Organization (WHO), cardiovascular disease is the leading cause of death in the world. Cardiovascular diseases are complications of the heart and the associated blood vessels that result from risks factors, such as physical inactivity, tobacco/alcohol consumption, and unhealthy diets. In 2016, the records indicate that cardiovascular disease accounted for 31 percent of mortalities globally, and 85 percent was due to heart attack and stroke (WHO, Cardiovascular Diseases, 2017). Although middle and low- income countries have experienced higher mortality rates (75 percent) due to cardiovascular diseases, wealthier countries experience similar trends of deaths from cardiovascular diseases. (WHO, Cardiovascular Diseases, 2017).

In the United States, cardiovascular disease was the leading cause of death, which accounted for approximately 900,000 deaths in 2016, or approximately 1 in every 4 deaths (Roth et al, 2018). The risk of heart disease increases after age 40 and places an economic burden on countries as the aging population is rising (Roth et al, 2018). Employers' chief targeted concern that drove wellness strategies were physical activity, smoking, and weight loss. As a result, previous studies suggested that wellness programs in the United States promote healthier lifestyles and manage current lifestyle epidemics 
(Mattke, Liu, Caloyeras, 2013). The trends of mortality rates due to cardiovascular complications have experienced a decrease. Other developed nations have experienced the same trends.

Every country's cardiovascular mortality rates differ because of the variation in their lifestyles, but still healthier nations focus on decreasing mortality rates. Studies on the health status of the Swedish population found that cancer followed by cardiovascular disease are the leading cause of mortality (Danielsson \& Berlin, 2012). Heart disease is also the leading cause of death in Italy accounting for more than 75,000 deaths in 2012 (WHO, Italy, 2018). The United Kingdom has experienced similar trends with heart diseases. Cardiovascular diseases are among the leading cause of death in the United Kingdom, accounting for approximately 26 percent of all deaths in the country (British Heart Foundation, 2018).

\section{Life Expectancy}

Life expectancy refers to the average number of years a person is predicted to live and varies by country across the world. The measure of life expectancy is the best comparable measure of the overall health of countries, and that is a vital component of this research. In 2016, the Global Health Observatory Data recorded the average life expectancy of the world's population at 72.0 years (WHO, WHO Mortality Database, 2018). Although the United States has the greatest economy in the world and is above the world's average life expectancy, the country still fails to lead in life expectancy globally (World Bank, 2018). Several factors that influence life expectancy, such as education and lifestyle, contribute to an individual's longevity and health status.

\section{METHODS}

Online databases were used to acquire data on each country's average life expectancy and cardiovascular mortalities per year from 2011-2015. The data on cardiovascular mortalities were collected from the World Health Mortality Database, while the data on life expectancy was retrieved from The World Bank's Database. Data on workplace wellness programs were collected from the October 2018 edition of the Global Wellness Economy Monitor (Global Wellness Institute, 2016) and the $5^{\text {th }}$ Global Wellness Survey (Hall, Hunt, Ratcliffe, 2012). Regression analysis were conducted to determine if a correlation exists between life expectancy, cardiovascular mortalities, and workplace wellness programs. Statistical analyses were conducted using the Statically Package for Social Sciences (SPSS), Version 25. Alpha and power levels were set at the traditional values for social science research $(0.05 ; 0.8)$ with the goal of maintaining good statistical power and significance.

\section{RESULTS}

Life expectancy data shows that the United States had the lowest average life expectancy from 2011 2015 among the countries examined (Table 1). Cardiovascular mortality data shows that the United States had the highest number of total death dues to cardiovascular disease from 2010 - 2014 (Table 2). Workplace wellness data shows that the United States is ranked number 1 in terms of the number of workplace wellness programs available (Table 3). Regression models were run to determine what relationships exist. Regression analysis found that life expectancy and heart disease are correlated with overall population $(\mathrm{p}=.044)$. A second regression analysis was conducted to determine if there is a relationship between average life expectancy, number of workers covered, and overall wellness expenditures. While not statistically significant $(\mathrm{p}=.317)$, results indicate a slight correlation between average life expectancy and number of workers covered by workplace wellness programs. A third regression analysis was conducted to determine if there is a relationship between the average number of heart disease mortalities, number of workers covered, and overall wellness expenditures. While not statistically significant $(\mathrm{p}=.073)$, results indicate a correlation between average number of heart disease mortalities and number of workers covered by workplace wellness programs. 
TABLE 1

LIFE EXPECTANCY OF THE UNITED STATES, SWEDEN, UNITED KINGDOM AND ITALY FROM 2011- 2015

\begin{tabular}{|l|l|l|l|l|l|}
\hline \multicolumn{5}{|c|}{ Life Expectancy } \\
\hline & 2011 & 2012 & 2013 & 2014 & 2015 \\
\hline United States & 78.64 & 78.74 & 78.74 & 78.84 & 78.69 \\
\hline Sweden & 81.80 & 81.71 & 81.96 & 82.25 & 82.21 \\
\hline United Kingdom & 80.96 & 80.91 & 81.01 & 81.31 & 80.96 \\
\hline Italy & 82.19 & 82.24 & 82.69 & 83.09 & 82.54 \\
\hline
\end{tabular}

(World Bank, 2018)

TABLE 2

TOTAL NUMBER OF CARDIOVASCULAR DEATHS IN THE UNITED STATES, SWEDEN, UNITED KINGDOM AND ITALY FROM 2011-2015

\begin{tabular}{|l|l|l|l|l|l|}
\hline \multicolumn{6}{|c|}{ Number of Cardiovascular Deaths } \\
\hline & 2011 & 2012 & 2013 & 2014 & 2015 \\
\hline United States & 375,295 & 371,469 & 370,213 & 364,593 & 366,801 \\
\hline Sweden & 14,304 & 14,087 & 13,190 & 12,573 & 12,121 \\
\hline United Kingdom & 74,036 & 73,683 & 73,024 & 69,163 & 69,783 \\
\hline Italy & 74,712 & 75,098 & 71,572 & 69,653 & 73,172 \\
\hline
\end{tabular}

(WHO, Cardiovascular Diseases, 2017)

TABLE 3

WORKPLACE WELLNESS MARKET IN UNITED STATES, SWEDEN, UNITED KINGDOM AND ITALY, 2018 (Global Wellness Institute, 2016)

\begin{tabular}{|l|l|l|c|}
\hline & $\begin{array}{l}\text { Number of Workers } \\
\text { Covered (millions) }\end{array}$ & Expenditures (USD millions) & Rank in 2016 \\
\hline United States & 83.8 & $\$ 15,678.80$ & 1 \\
\hline Sweden & 2.6 & $\$ 669.5$ & 12 \\
\hline United Kingdom & 14.5 & $\$ 2,536.1$ & 4 \\
\hline Italy & 9.3 & $\$ 1,671.6$ & 7 \\
\hline
\end{tabular}




\section{DISCUSSION}

The comparative analysis of the study identifies the difference in trends over the five- year period. Although the United States is ranked first in the workplace wellness market in terms of number of programs offered and workplace wellness expenditures, European countries under investigation still have better health outcomes. Sweden had a significant improvement in cardiovascular mortalities from 20142015 that catapulted the country past the U.S. An interesting finding was that employers in Sweden have pushed the concept of mandatory on the job exercise in their establishments. In 2014, after companies implemented the idea of compulsory exercise in their workplace culture, a 22 percent decline in work absences was observed (Bas-Wohlert, 2018). According to the CDC, approximately 79 percent of adults do not meet the recommended physical activity guidelines (CDC, Physical Activity Data, 2018). A recent study found that approximately 77 percent of employees would work out more if their employer had a gym that they could use during work hours, and approximately 66 percent of employees would still work for their employer if in office workouts were mandatory (Treadmill Reviews, 2018).

The complexity of a nation's life expectancy is influenced by multiple factors which are entwined in a country's structure and culture. The U.S. system is composed of a private and a public sector. While the public sector focuses on the improvement of an individual's overall health, the private sector's leading driving factors concerning wellness programs are reducing insurance premium costs and reducing sick and disability absences (Hall, Hunt, Ratcliffe, 2012). Whereas in Europe, the government funds the majority of healthcare and advocates workplace wellness programs where they can alleviate chronic diseases (Global Wellness Institute, 2016). According to the Bureau of Labor Statistics, 39 percent of private industry employees and 63 percent of state and local government employees in the US had access to wellness programs (U.S. Bureau of Labor Statistics, 2018). Furthermore, research has shown that salary is an indicator of access to workplace wellness programs. The Global Wellness Institute found that among private industry workers 63 percent in the highest 10 percent had access, whereas 15 percent of the lowest 10 percent had access to wellness programs (Global Wellness Institute, 2016). The low-income populations are a vulnerable group which makes them more susceptible to illnesses. Although no statistically significant impact was found on the number of workers covered and expenditures of workplace wellness programs on life expectancy or cardiovascular mortalities, having limited access to wellness programs hinders progression to the U.S. in improving. Evenly providing access to workplace wellness programs in private sectors for all income wages could help to improve life expectancy and cardiovascular mortalities.

\section{CONCLUSION}

Workplace wellness programs are tools for improving and promoting healthier lifestyles. The U.S. and Western Europe have invested a significant amount of resources on wellness programs, however, the trends indicate that the U.S. still falls short in health outcomes in terms of life expectancy and cardiovascular mortalities compared to Italy, Sweden, and the United Kingdom. Workers in the US have approximately twice the access to wellness programs as European workers. Nevertheless, a higher proportion of Europeans are meeting the physical requirements than Americans. Workplace wellness programs are not the sole factor that drive health outcomes, but the initiatives have resulted in betterment of an individual's health.

Although there was insufficient data that would have led to more discoveries on the impact of wellness programs, we found that life expectancy and heart disease are correlated with size of the overall population. The government is heavily involved in European countries by advocating wellness programs to mitigate chronic diseases, whereas private companies in the U.S. limit the number of workers with access to wellness programs based on income. As a result, low income populations have restricted access to workplace wellness programs hindering the progression of health outcomes in the U.S. Further research needs to be conducted in order to recommend the appropriate programs for private employer and to examine the extent of workplace wellness programs' impact. 


\section{REFERENCES}

Bas-Wohlert, C. (2018). Mandatory exercise at the office, Sweden's latest craze. Retrieved from https://medicalxpress.com/news/2018-02-mandatory- office-sweden-latest-craze.html

Biffi, A., \& Volpe, M., et al. (2018). Ferrari Corporate Wellness Program: Results of a Pilot Analysis and the "Drag" Impact in the Workplace. High Blood Pressure \& Cardiovascular Prevention, 25(3), 261-266.

Buck Consultants. (2010). Working Well: A Global Survey of Health Promotion and Workplace Wellness Strategies. Retrieved from https://www.buckconsultants.com/portals/0/events/2012/web/waworking-well-what- next-wellness-2012-1212.pdf

Cardiovascular diseases (CVDs). (2017). World Health Organization. Retrieved from https://www.who.int/news-room/fact-sheets/detail/cardiovascular-diseases-(cvds)

CDC. (2016, April 01). Worker Productivity Measures. Retrieved from https://www.cdc.gov/workplacehealthpromotion/model/evaluation/productivity.html

CDC. (2016, May 13). Workplace Health Model. Retrieved from https://www.cdc.gov/workplacehealthpromotion/model/index.html

CDC. (2018). Physical Activity Data. Retrieved from https://www.cdc.gov/physicalactivity/data/facts.htm

Center for Medicare and Medicaid Services. (2018, January 08). National Health Expenditure Data. Retrieved from https://www.cms.gov/Research-Statistics- Data-and-Systems/Statistics-Trendsand-Reports/NationalHealthExpendData/index.html

Corporate wellness industry by company number U.S. 2007-2021 | Statistic. (2018). Statista. Retrieved from https://www.statista.com/statistics/555669/us-corporate- wellness-service-companies-totalnumber/

Danielsson, M., \& Berlin, M. (2012). Health in the working-age population: Health in Sweden: The National Public Health Report 2012. Chapter 4. Scandinavian Journal of Public Health, 40(9), 72-94.

Employee access to wellness programs in 2017. (2018). U.S. Bureau of Labor Statistics. Retrieved from https://www.bls.gov/opub/ted/2018/employee-access- to-wellness-programs-in-2017.htm

Gånedahl, H., Viklund, P. Z., Carlén, K., Kylberg, E., \& Ekberg, J. (2015). Work-site wellness programmes in Sweden: A cross-sectional study of physical activity, self-efficacy, and health. Public Health, 129(5), 525-530.

Global Wellness Institute. (2016). The Future of Wellness at Work. Retrieved from https://globalwellnessinstitute.org/press-room/press-releases/global-wellness- institute-releasesreport-and-survey-on-the-future-of-wellness-at-work/

Greenbaum, E. (2011) Achieving a healthy workforce worldwide. Global Health Benefits Institute. Retrieved from https://www.businessgrouphealth.org/pub/?id=f2f7fb7c-2354-d7145120Da400b918c15d

Hall, B., Ratcliffe, D., \& Hunt, R. (2012). Working Well: What's next for wellness? Retrieved from https://www.buckconsultants.com/portals/0/events/2012/web/wa- working-well-what-nextwellness-2012-1212.pdf

International Monetary Fund. (2018, April). Gross domestic product (GDP) ranking by country 2017. Retrieved from https://www.statista.com/statistics/268173/countries-with-the-largest-grossdomestic- product-gdp/

Italy. (2018). World Health Organization. Retrieved from https://www.who.int/countries/ita/en/

Life expectancy at birth, total (years). (2018). World Bank. Retrieved from https://data.worldbank.org/indicator/sp.dyn.le00.in?end=2014\&start=2013\&year_low_de sc=true

Mattke, S., Liu H., \& Caloyeras J., et al. (2013). Workplace Wellness Programs Study: Final Report. Rand Health Quarterly, 3(2), 7.

Reward \& Employee Benefits Association. (2017). Employee Wellbeing Research 2017: The evolution of workplace wellbeing in the UK. London, U.K.: Reba Group. 
Roth, G. A., \& Murray, C. J. L. (2018). The Burden of Cardiovascular Diseases Among US States, 19902016. JAMA Cardiology, 3(5), 375-389.

UK Factsheet. (2018). British Heart Foundation. Retrieved from https://www.bhf.org.uk/what-we-do/ourresearch/heart-statistics

WHO Mortality Database. (2018, May). World Health Organization. Retrieved from http://apps.who.int/healthinfo/statistics/mortality/whodpms/

Working Out During the Workweek. (2018). Treadmill Reviews. Retrieved from https://www.treadmillreviews.net/working-out-during-the-workweek/ 